\title{
FATORES CRÍTICOS DE SUCESSO NA AQUISIÇÃO DE COMPETÊNCIA NO ESTÁGIO CURRICULAR SUPERVISIONADO: O CASO DOS CURSOS DE ENGENHARIA DO CEFET-PR
}

\section{CRITICAL FACTORS OF SUCCESS IN COMPETENCE ACQUISITION IN THE SUPERVISED CURRICULAR TRAINING PERIOD: THE CASE OF CEFET-PR ENGINEERING COURSES}

\author{
Antonio Carlos de Francisco ${ }^{1}$; Neri dos Santos $^{2}$ \\ ${ }^{1}$ CEFET-PR/Unidade de Ponta Grossa, acfrancisco@pg.cefetpr.br \\ ${ }^{2}$ Universidade Federal de Santa Catarina, neri@eps.ufsc.br
}

Recebido para publicação em: 22/11/2004 Aceito para a publicação em: 25/02/2005

\section{RESUMO}

O objetivo do presente estudo foi: Identificar os fatores críticos de sucesso que permitam ao aluno dos Cursos de Engenharia do CEFET-PR adquirir competências durante a realização do Estágio Curricular Supervisionado (ECS). Para a realização do estudo, o problema central foi: Quais são os fatores críticos de sucesso na aquisição de competências, por parte dos alunos-estagiários na realização do seu ECS? O método utilizado foi o indutivo. A pesquisa foi caracterizada como aplicada; qualitativa; exploratória e como estudo de caso. A coleta de dados foi através da entrevista semi-estruturada. As inferências foram através da análise qualitativa de conteúdo. A pesquisa de campo desenvolveu-se em empresas, com supervisores de estágio, e no CEFET-PR, com coordenadores de estágio e com alunos-estagiários. As temáticas perquiridas foram: a coordenação, orientação e supervisão do ECS; possibilidades e limitações para a aquisição $e$ o compartilhamento de novos conhecimentos e competências. Foram constatados os seguintes aspectos: os principais fatores críticos de sucesso na aquisição de competências durante a realização do ECS dizem respeito a deficiências na orientação, na utilização dos documentos gerados quando da realização do ECS e na defesa pública do estágio, na Instituição de Ensino pesquisada; na supervisão e ambientação do estagiário nas empresas.

Palavras-chave: Estágio, Aquisição de Competência, Fatores Críticos de Sucesso

\section{Introdução}

No contexto educacional atual, a informação, o conhecimento e a competência assumem um papel importantíssimo para as Instituições de Educação Superior (IES), para os futuros profissionais - liberais ou empregados - e para as empresas que se utilizarão destes profissionais. Pode-se dizer que a quantidade de informação, de conhecimento e, com isso, a aquisição de competência, cresce e circula a uma proporção nunca vista anteriormente. 
Aliado a este cenário, a lei máxima que trata da educação brasileira, Lei de Diretrizes e Bases - LDB, modificou amplamente o panorama existente para a educação do País. A nova LDB reestruturou a educação nacional, criou novas modalidades de ensino e avançou em diversos campos e níveis da educação.

Para Moretto (1999, p.12) o rumo da educação mudou, deslocou-se da "aquisição de conteúdos para a aquisição de habilidades e competências na gerência de conteúdos”. Apesar disto, talvez, a escola não tenha percebido esta mudança de rumo.

Neste caso, segundo Moretto (1999, p. 47), o desenvolvimento de recursos para a aquisição de competências se dará através:

- de conteúdos específicos;

- de habilidades;

- de novas linguagens;

- de valores culturais e;

- do desenvolvimento de emoções.

Assim o autor sugere um novo rumo para a educação, ou seja, a "educação para competências". Este novo rumo para a educação faz com que as IES sejam instituições voltadas, sobretudo, ao compartilhamento, à criação e à transferência de conhecimentos e de competências.

No entanto, apesar de prever a aquisição de competências e habilidades aos egressos, não determina como o ensino deve ser conduzido para se alcançar tal objetivo. Ao apresentar as diretrizes para a realização do estágio, as mesmas ficam restritas à carga horária e ao período para sua realização. Mesmo subentendido, a possibilidade de transferência e aquisição de conhecimentos e de competências ficam esquecidas nesta parte das diretrizes.

Ao se compartilhar o conhecimento adquirido pelo aluno-estagiário durante seu Estágio Curricular Supervisionado (ECS), pode-se ter uma importante fonte de atualização curricular e, ao mesmo tempo, reconhece-se neste processo de transferência de conhecimento a interação com o ambiente institucional, ou seja, a empresa onde o aluno realiza o estágio, aprende com o estagiário e o estagiário aprende nela.

Em função desta realidade, o trabalho se propõe a identificar os fatores críticos de sucesso na aquisição de competência durante a realização do estágio curricular supervisionado nos cursos de engenharia do CEFET-PR.

O presente estudo, em função dos objetivos estabelecidos, pode ser classificado como exploratório. A abordagem é qualitativa. Em função dos procedimentos técnicos empregados, a pesquisa é classificada como um estudo de caso. O método de pesquisa utilizado foi o indutivo. A técnica de coleta de dados utilizada foi a entrevista semi-estruturada. O corpus documental da pesquisa é composto por com alunos-estagiários, supervisores de estágio dos estagiários 
entrevistados e coordenadores de estágios dos cursos de Engenharia do CEFET-PR. Para a análise dos dados, o método utilizado foi análise do conteúdo.

\section{Competência}

Em seu livro, Objetivo Competência: por uma nova lógica, Zarifian (2001) apresenta uma discussão entre qualificação e conhecimento. Zarifian (2001, p. 19) aponta que os principais fatores que influenciaram no aparecimento do termo competência foram o aumento da complexidade do trabalho e o aumento da quantidade e do tratamento de eventos. Para o autor, estas foram as duas principais causas do aparecimento do termo competência. Para Zarifian (1998, p. 20), dois aspectos são essenciais no que se pode chamar de competência. O primeiro aspecto apontado pelo autor é o "assumir responsabilidade"; o segundo aspecto é o "desenvolvimento de uma atitude reflexiva face ao trabalho".

Lévy (1996, p. 60) define competência como "uma capacidade continuamente alimentada de aprender e inovar, que pode se atualizar de maneira imprevisível em contextos variáveis”.E, assim como o conhecimento e a informação, a competência não é consumida enquanto é utilizada. No mesmo sentido caminha Resende (2000, p. 32), quando define competência como sendo "a transformação de conhecimentos, aptidões, habilidades, interesses, vontade, etc. em resultados práticos".

Para Sveiby (1998, p. 42) a competência de um indivíduo é constituída por cinco elementos interdependentes. São eles:

- Conhecimento Explícito. O conhecimento explícito envolve conhecimento dos fatos e é adquirido principalmente pela informação, quase sempre pela educação formal.

- Habilidade. Esta arte de "saber fazer" envolve uma proficiência prática - física e mental - e é adquirida, sobretudo por treinamento e prática. Inclui o conhecimento de regras de procedimento e habilidades de comunicação.

- Experiência. A experiência é adquirida principalmente pela reflexão sobre erros e sucessos passados.

- Julgamentos de valor. Os julgamentos de valor são percepções do que o indivíduo acredita estar certo. Eles agem como filtros conscientes e inconscientes para o processo de saber de cada indivíduo.

- Rede social. A rede social é formada pelas relações do indivíduo com outros seres humanos dentro de um ambiente e uma cultura transmitidos pela tradição.

Resende (2000, p. 58) apresenta uma classificação bastante abrangente sobre o tema Competência. Apesar de abrangente, não deve ser considerada como completa, devendo, portanto, ser objeto de estudos mais profundos nos meios acadêmicos e nas próprias organizações. 
Classificação quanto a domínio e aplicação:

Pessoas potencialmente competentes: desenvolveram e possuem características, atributos e requisitos, tais como conhecimentos, habilidades, habilitações, mas não conseguem aplicá-los objetivamente na prática, ou não tiveram a oportunidade de mostrar resultados nas ações e nos trabalhos através deles.

Pessoas efetivamente competentes: quando aplicam essas características, atributos e requisitos e mostram claramente resultados e êxitos em suas ações e atividades.

Categorias diversas de competência:

Competências técnicas: de domínio apenas de determinados especialistas. Competências intelectuais: competências relacionadas com aplicação de aptidões mentais.

Competências cognitivas: competência que é um misto de capacidade intelectual com domínio de conhecimento.

Competências relacionais: competências que envolvem habilidades práticas de relações e interações.

Competências sociais e políticas: competências que envolvem ao mesmo tempo relações e participações em sociedade.

Competências didático-pedagógicas: competências voltadas para educação e ensino.

Competências metodológicas: competências na aplicação de técnicas e meios de organização de atividades e trabalhos.

Competências de lideranças: são competências que reúnem habilidades pessoais e conhecimentos de técnicas de influenciar e conduzir pessoas para diversos fins ou objetivos na vida profissional ou social.

Zarifian (2001) ainda apresenta outras classificações para o termo competência. Entre estas outras classificações está o que o autor chama de "competências de fundo ou competências de recursos". As competências de fundo são, segundo o autor, cristalizadas em certos campos, entre eles: "na aprendizagem do domínio da linguagem e de seus usos, na formação do interentendimento nas situações de comunicação, na importante aprendizagem da reflexão e da aprendizagem" (IBID, 175). Estas competências são adquiridas na relação educativa. Pode-se dizer que as competências de fundo são as principais competências desenvolvidas no ambiente acadêmico.

Quando o assunto é o ECS, para se atingir um dos objetivos a que a atividade se destina, que neste caso é a aquisição de competência, aceita-se como pressuposto que durante seu estágio o aluno alcance uma progressão na aprendizagem. 


\section{Aquisição e transferência de competência}

Basicamente, existem duas formas essenciais, admitidas pela ciência, para a aquisição de competências: a aprendizagem por descoberta a partir da ação, levando a um saber fazer, e a aprendizagem por instrução, que consiste em comunicar um conhecimento, ou em forma verbal, ou formulando-o num texto, conduzindo o estudante a um saber (RICHARD; 1974).

Apesar de ser uma maneira mais lenta, as pessoas preferem descobrir o conhecimento por meio de descobertas, pois, o indivíduo que aprende, lança mão de todos os seus sentidos. Já a transferência e a aquisição de competências por intermédio da instrução é mais rápida, pois a sua distribuição pode alcançar um número muito grande de indivíduos.

Sveiby (1998, p. 54), aponta as principais diferenças entre a aquisição de competência pela instrução e a aquisição de competência pela descoberta (aprender fazendo). Para o autor, a transferência de competência pela informação: transfere informações articuladas; é independente do indivíduo; estática; rápida; codificada; e possui fácil distribuição em massa.

Por sua vez, a transferência da competência pela descoberta: transfere capacidades articuladas e não-articuladas; e dependente e independente; é dinâmica; lenta; não-codificada; e de difícil distribuição em massa.

No que diz respeito à transferência da competência pela informação, Zarifian (IBID, p. 169) aponta duas constatações que se está vivenciando em nossos dias, e conforme o autor, as duas excludentes. A primeira se refere à exclusão dos jovens que saem do sistema educacional sem se diplomar e a segunda, quanto mais alto o nível do diploma, maior serão suas chances de inserção profissional.

\section{Situação escolar e situação de trabalho}

As discussões que tratam das diferenças entre o mundo empresarial e o mundo universitário não são novas. Grynszpan (1999, p. 23), reconhece estas diferenças, pois segundo o autor, "os dois setores, universitário e empresarial, têm dinâmica e objetivos bem distintos e muitos desacordos existem e continuarão a existir. As contradições não ocorrem apenas no Brasil, é uma realidade comum a todos os países".

Para Plonski (1999, p. 7), atualmente são pouco freqüentes as manifestações públicas de "confronto ideológico com a instituição universitária. Cabe lembrar que esta já foi vista, em outras épocas, como foco de interesses antagônicos aos das empresas." 
Uma forma reconhecida de Cooperação Universidade-Empresa (CUE) é o estágio. Pode-se dizer que o estágio é um ambiente privilegiado para a aquisição de conhecimentos e de competências, principalmente para os alunos participantes da atividade. Através do estágio a IE tem condições de tomar conhecimento das atividades desenvolvidas nas empresas. Neste sentido, as empresas podem utilizar o estágio, através do estagiário, para conhecer a IE que fornece seus profissionais e a que ponto esta Instituição está formando profissionais adequados às suas necessidades. Com isso, pode-se supor que a possibilidade de se gerenciar os conhecimentos e as competências adquiridas pelos estagiários durante a atividade pode trazer benefícios para todos os seus participantes (aluno-estagiário, IES e empresas concedentes de vagas de estágio).

\section{Estágio}

Ao se pensar em formas concretas da preparação ao mundo do trabalho que cabe às IES poderá ser facilmente constatado que uma das formas mais efetivas é o ECS. O Estágio é parte integrante da formação do estudante, é uma atividade desenvolvida e planejada pela IES, e tem, a princípio, como finalidade principal, a complementação formativa.

O estágio possibilita para as IES a obtenção de subsídios para avaliar a efetividade com que se está desenvolvendo o processo ensino-aprendizagem, correlacionando os conteúdos profissionalizantes do currículo com as necessidades do mundo do trabalho. Observa-se que os subsídios levados em consideração para a avaliação da efetividade do desenvolvimento do processo ensino-aprendizagem estão pautados basicamente no número de estagiários efetivados após a conclusão da atividade. Tem que se reconhecer que esta é uma maneira de se avaliar, mas não pode ser a única. O aluno-estagiário tem condições de colaborar mais ativamente com o processo ensinoaprendizagem. Para isso as IES podem criar mecanismos para gerenciar o conhecimento criado ou transformado por esse aluno durante a atividade.

Em linhas gerais, pode-se dizer que, o referido estágio destina-se a oportunizar ao futuro profissional complementação do processo ensino-aprendizagem através de experiências práticas vividas no ambiente de trabalho.

\section{Apresentando as entrevistas}

$\mathrm{Na}$ maioria dos casos, os supervisores, orientadores e coordenadores de estágio possuem uma boa experiência no assunto. O tempo de experiência como supervisor de estágio varia de seis (06) meses a dezoito (18) anos; para os coordenadores de estágio, por sua vez, de um (01) a cinco 
(05) anos. 75\% dos alunos-estagiários entrevistados, ou seja, seis (06), realizaram estágio não obrigatório, o que demonstra que para a maioria dos entrevistados, o ECS não é uma novidade.

Os alunos-estagiários entrevistados não apontaram diferenças significativas o estágio não obrigatório e o curricular. A única diferença apontada pelos alunos-estagiários entrevistados, é quanto ao tipo de atuação no estágio, como por exemplo, o estágio em um programa de pósgraduação e o estágio em uma empresa. No mais, em ambos os casos o estágio é idêntico.

Em todos os casos, os entrevistados apontaram a existência de auxílio financeiro para a realização da atividade. Em duas (02) coordenações de curso, quem escolhe o orientador de estágio é o coordenador, e conforme seus depoimentos, levam em conta, no momento da indicação do professor-orientador, a afinidade deste docente com a área que o estagiário vai realizar o estágio. Em um dos casos, a escolha do professor-orientador de estágio fica por conta do contato entre o aluno-estagiário e o professor. O quarto não deixou clara a maneira como é realizada a escolha do orientador, se é o próprio aluno-estagiário ou o coordenador da atividade.

As atividades que o estagiário deve desenvolver durante a realização de seu ECS devem estar previstas em seu plano de estágio. Os procedimentos para elaboração do plano de estágio são diferentes de coordenação para coordenação. Um dos coordenadores entrevistados declarou que o supervisor não tem nada a ver com a IE no momento da realização do plano de estágio, o que cria um confronto com o regulamento da atividade na instituição, que prevê justamente a participação deste supervisor na elaboração do plano de estágio.Na maioria dos casos o plano de estágio não sofre alterações. Um dos motivos apontados pelos entrevistados é o fato de se propor um plano de estágio amplo.

No que diz respeito à adequação do estágio ao curso a que o estagiário está vinculado, para os alunos-estagiários e para os supervisores de estágio entrevistados, dos dezesseis (16) entrevistados, treze (13), ou 81,25\%, declararam que os estágios que estavam participando ou supervisionando estava adequado ao curso a que o estagiário estava matriculado. Um (01) declarou que era um estágio mais adequado a um curso técnico. Um (01), que existe problema por parte da empresa no momento da seleção deste estagiário, o que pode levar a uma inadequação entre o estágio e o curso a que o estagiário está vinculado. Uma preocupação ocorreu quando um supervisor de estágio declarou que a empresa não tem "uma preocupação muito grande em relação a adaptar o estágio ao curso".

Quanto às condições ofertadas pelas empresas concedentes de vagas de estágio para a realização da atividade, os alunos-estagiários entrevistados atestaram como satisfatória, sendo que os mesmos não perceberam a diferença entre eles, estagiários, e os funcionários da empresa. Por parte das empresas, cinco (05) delas declararam que as condições são as mesmas de um funcionário. Em três (03) existe um diferencial neste aspecto. Apesar destas empresas não possuírem um sistema 
estruturado para o recebimento de estagiários, os seus supervisores possuem a preocupação em ambientar este indivíduo na organização.

A avaliação do estágio é feita de acordo como regulamento por três (03) coordenadores de estágio, ou por três dos quatro cursos de engenharia existente na instituição. Apenas um (01) entrevistado citou a necessidade de se cobrar relatórios parciais no decorrer da execução da disciplina. Em uma (01) das coordenações não se configurou a existência do seminário de estágio, nem mesmo se esta atividade é aberta ao público. A avaliação é feita, segundo o coordenador de estágio, pelo relatório da atividade.

Apenas um (01) dos quatro (04) coordenadores de estágio entrevistados declarou que utiliza as informações obtidas através do estágio, no sentido de monitorar os conteúdos ministrados nos curso.

Os entrevistados reconhecem que o ECS oportuniza uma contribuição significativa na formação dos futuros profissionais. Esta contribuição é no que diz respeito ao aprendizado técnico e na comprovação da teoria vivenciada na escola com a prática vivenciada na empresa, mas, a contribuição mais evidenciada, diz respeito ao contato com o mundo do trabalho, ao contato com pessoas e ambientes diferentes, com exigências diferentes, especificamente com o relacionamento com outras pessoas em um ambiente competitivo. Para um dos entrevistados, a principal contribuição do ECS é a possibilidade do estagiário conseguir um emprego.

As dificuldades apontadas pelos entrevistados variam de área de atuação. Para os coordenadores de estágio estão no excesso de alunos para orientar e falta de autonomia. Para os supervisores de estágio, é a falta de um processo específico na empresa para ambientar estes alunos e a desvinculação entre o mundo acadêmico e do mundo profissional. Para os alunos-estagiários entrevistados é a distância entre o estágio, a IE e a casa, o número de horas diárias elevado para a realização da atividade e a falta de supervisão. Para todos os segmentos entrevistados uma dificuldade foi constante: a dificuldade no relacionamento com outras pessoas.

Em contrapartida, a maioria dos alunos-estagiários entrevistados reconhece a existência de autonomia para a resolução de problemas, mas, segundo um dos entrevistados, "É uma autonomia fiscalizada".Três (03) dos alunos entrevistados declararam que possuíam autonomia, principalmente na parte técnica. A autonomia dada também pelos supervisores de estágio é na parte técnica. Em um caso específico, e extremo, um supervisor de estágio (entrevistado S5) deixou sob a responsabilidade do estagiário o desenvolvimento de um novo componente a ser fabricado pela empresa.

A autonomia para o estagiário na resolução de problemas, na maioria dos casos, acontece sempre sob a supervisão de um (01) responsável conforme vai desenvolvendo suas atividades durante o estágio, o que se assemelha muito ao ganho de autonomia por um funcionário. 
A maioria dos alunos entrevistada permanece subordinada a um mesmo setor durante toda a duração de seu ECS, o que por si só impede que estes estagiários possuam uma visão completa da empresa onde realizam a atividade.

Para os entrevistados, alunos-estagiários e supervisores de estágio, as aptidões intelectuais vão sendo desenvolvidas conforme o desenrolar das atividades executadas e da vivência do dia-adia do estagiário na empresa.

Segundo os alunos-estagiários e os supervisores de estágio entrevistados, as habilidades pessoais são desenvolvidas, durante o ECS através de processos de negociação existentes no decorrer do seu estágio. Um dos supervisores de estágio entrevistado declarou que a empresa "não consegue formar pessoas neste sentido, acho que ela já tem que vir formada. É a bagagem dela, não tem muito como formar indivíduos, formar caráter dentro da empresa".

Os alunos-estagiários não conseguiram observar muitas possibilidades de exercitar as habilidades de liderança. Para os alunos-estagiários entrevistados a principal situação onde ocorre uma possibilidade de se liderar alguém ou um grupo é quando na empresa entram novos estagiários. Para os coordenadores de estágio as habilidades de liderança são natas. Os coordenadores de estágio entrevistados não visualizaram possibilidades para o estagiário desenvolver habilidades de liderança no ECS.

A formação escolar básica utilizada na maioria dos estágios é a formação obtida na IE, no respectivo curso. Em um dos casos a formação de um técnico na área era suficiente para o desenvolvimento das atividades. A formação complementar utilizada para a realização dos ECS foi a experiência e a vivencia obtida em cursos técnicos, nas áreas de relações humanas, computação, e de uma língua estrangeira (inglês, espanhol, francês e alemão), além de um conhecimento mais aprofundado em informática.

Sete (07) dos oito (08) alunos-estagiários entrevistados declaram a utilização de experiências anteriores, mais especificamente em outros estágios, para a realização do estágio em questão. Para os supervisores de estágio entrevistados, a utilização de experiências em outros estágios, principalmente nos estágios dos cursos técnicos, por parte dos estagiários auxiliou na realização dos atuais estágios.

As situações para o estagiário assumir responsabilidades, segundo os alunos-estagiários entrevistados, ocorrem no dia-a-dia do estágio. Depende das atividades e do interesse despertado pelo estagiário. Em algumas empresas existem situações onde os estagiários possuem as mesmas responsabilidades de um engenheiro formado e com certo grau de experiência.

Todos os entrevistados entendem que o estágio é um ambiente rico na transformação de conhecimento explícito em conhecimento tácito. Isto ocorre devido ao fato do aluno chegar a vivenciar todas as fases existentes na elaboração de um produto ou um serviço. 
Para os entrevistados, alunos-estagiários, supervisores de estágio e coordenadores de estágio, existe diversidade nas situações vivenciadas pelos alunos-estagiários, mas esta diversidade é restrita a um setor ou departamento. De certa maneira, os estagiários acabam vivenciando todas as situações que acontecem em seu setor, mas não em toda empresa. Para os supervisores de estágio e coordenadores de estágio entrevistados, o aluno, durante seu estágio vivencia uma grande quantidade de diferentes atividades.

\section{Considerações finais}

Com o estudo pode-se observar que os fatores críticos de sucesso na aquisição de competências, por parte dos alunos na realização de seu ECS são os seguintes:

1- Trabalho de orientação e supervisão de estágio: não existe o comprometimento dos orientadores e supervisores com a questão da aquisição de competências e de conhecimentos por parte dos estagiários. Os orientadores não reconhecem o ECS como uma importante fonte de atualização dos conteúdos ministrados em seus cursos. Não existem reuniões regulares com estagiários e a criação de espaços para troca de informações entre os estagiários;

2- Comunicação e disponibilidade de documentos: os documentos gerados através da realização do estágio, principalmente o relatório de estágio, não são tornados públicos na IE pesquisada;

3- Ambientação do estagiário na empresa: não existe na empresa um sistema ou processo de ambientação do estagiário. O aluno é tratado como um funcionário novo na empresa;

4- A presença na defesa pública do estágio não é obrigatória aos alunos do curso. Na realidade, os alunos que estão diretamente envolvidos com a sua defesa de estágio, dificilmente participam participem desta atividade;

5- A possibilidade de compartilhamento de conhecimento e competência adquirido é bastante restrita. A efetivação da mesma, quando ocorre, acontece pelo canal informal.

Mesmo assim, existem possibilidades para a aquisição de competências e de novos conhecimentos pelo aluno-estagiário durante a realização de seu ECS. O aluno durante a realização de seu ECS adquire competência de diversas ordens, principalmente competências técnicas e competências de fundo (ZARIFIAN, 2001).

A competência técnica adquirida neste caso é em uma área específica ao setor ou atividade desenvolvida pelo estagiário na empresa. Já a aquisição das competências de fundo acontece no diaa-dia do estagiário, na melhoria de sua capacidade de se relacionar com colegas e superiores, de analisar e resolver problemas e no cumprimento dos requisitos legais para a conclusão da atividade. 


\section{ABSTRACT}

The objective of the present study was: Identify the critical factors of success that allow the engineering courses student of CEFET-PR to acquire competences during the supervised curricular training. For the carrying out of the study, the central problem was: Which are the critical factors of success in competences acquisition, on students' behalf in the carrying out of their supervised curricular training? The method used for the research was the inductive one. The research was characterized as applied; qualitative; exploratory and as a case study. The instrument used for the data collection was the half-structuralized interview. The inferences were made through the qualitative analysis of content. The research was developed in companies, with training period supervisors, and at CEFET-PR, with period training coordinators and students trainees. The themes investigated were: the coordination, orientation and supervision of supervised curricular training; possibilities and limitations for the acquisition and sharing of new knowledge and competences. The following aspects were evidenced: the main critical factors of success for the acquisition of competences during the carrying out of the supervised curricular training have to do with the deficiencies in the orientation, the supplying of documents generated when the supervised curricular training carries out and in the public defense of the training period, in the researched Education Institution; in the supervision and self adjustment of the trainees in the companies.

Keywords: Training Period, Competence Acquisition, Critical Factors of Success

\section{Referências}

BARDIN, L. Análise de conteúdo. Lisboa: Edições 70, 2002.

BRASIL. Lei no 9.394, de 20 de dezembro de 1996. [Estabelece as diretrizes e bases da educação nacional]. Diário Oficial da República Federativa do Brasil, Brasília, DF, 23 dez. 1996.

RYNSZPAN, F. A Cooperação da universidade moderna com o setor empresarial. Revista de Administração, São Paulo, v. 34, n. 4, p. 23-31, out./dez. 1999.

LÉVY, P. O que é virtual? São Paulo: Ed. 34, 1996.

MORETTO, V. P. Construtivismo: a produção do conhecimento em aula. Rio de Janeiro: DP\&A, 1999.

PLONSKI, G. A. Cooperação universidade-empresa: um desafio gerencial complexo. Revista de Administração, São Paulo, v. 34, n. 4, p. 5-12, out./dez. 1999.

RESENDE, E. O livro das competências: desenvolvimento das competências - a melhor auto-ajuda para pessoas, organizações e sociedade. Rio de Janeiro: Qualitymark, 2000.

RICHARD, J. F. Attention et apprentissage. Paris : PUF, 1974.

SVEIBY, K. E. A nova riqueza das organizações. Rio de Janeiro: Campus, 1998.

ZARIFIAN, P. A gestão da e pela competência. In: SEMINÁRIO INTERNACIONAL EDUCAÇÃO PROFISSIONAL, TRABALHO E COMPETÊNCIAS, 1996, Rio de Janeiro. Anais... Rio de Janeiro: SENAI/DN-CIET, 1998. p. 15 - 24.

Objetivo competência: por uma nova lógica. São Paulo: Atlas, 2001. 